\title{
CORRESPONDENCE
}

\section{Does risk to humans justify high cost of fighting bovine TB?}

SIR - The UK government's strategy for controlling bovine tuberculosis (TB) is to work with stakeholders to reduce the economic impact of the disease and to maintain publichealth protection, as well as animal health and welfare. In a nationwide programme, the Department for Environment, Food and Rural Affairs is investing between $£ 74$ million and $£ 99$ million a year on continuing cattle surveillance and control, slaughterhouse inspections, heat treatment of milk, occupationalhealth controls and monitoring for human cases (see http://tinyurl. com/578s5x).

The number of infected cattle herds increased from 88 in 1986 to 5,539 in 2005 (P. D. O. Davies J. R. Soc. Med. 99, 539-540; 2006). However, this increase has not been mirrored by an increase in zoonotic TB in humans. Between 1993 and 2003, there were 315 cases of bovine TB confirmed in humans: a mean number of 28 cases per year. All 50 isolates of Mycobacterium bovis, the microorganism responsible, that were recovered from humans between 1997 and 2000 have been investigated (A. L. Gibson et al. J. Clin. Microbiol. 42, 431-434; 2004), and of these, 15 had not been previously recorded in the UK cattle population.

Of the human cases of bovine $\mathrm{TB}, 72 \%$ of those infected were more than 50 years old (suggesting reactivation of an infection acquired before routine milk pasteurization was introduced), and many of the remaining cases were people born abroad. That leaves only a very small number of potential cases of transmission from present-day UK cattle, of which just two have been confirmed (R. M. M. Smith et al. Emerg. Infect. Dis. 10, 539-541; 2004).

Since the introduction of milk pasteurization, TB in humans caused by $M$. bovis has virtually disappeared in the United Kingdom. Consequently, the disease poses a negligible threat to public health.

Why then should a major intervention programme, proposed badger culling and vaccine research now be necessary to control it? The overwhelming societal cost of bovine TB is directly attributable to the costs of running the eradication programme and the associated research into control.

In the absence of significant transmission to humans, this question urgently needs to be addressed. Controlling bovine TB should be justified only in economic terms of reducing losses in animal productivity. Paul Torgerson Ross University, PO Box 334, St Kitts, West Indies and Institute for Parasitology, University of Zurich, Switzerland e-mail: ptorgerson@rossvet.edu.kn David Torgerson Department of Health Sciences, University of York, York Y010 5DD, UK

\section{Childcare not enough to make a science career family-friendly}

SIR - Amanda Goh writes soberly in Naturejobs of her expectation that, as a postdoc, having a baby will almost certainly undermine her career prospects ('The coming challenge' Nature 455, 704; 2008). She also acknowledges that being a mother while continuing to pursue a scientific career "may come at the cost of one's marriage".

Goh hits the nail on the head. In our experience, the predominant reason why women drop out of scientific careers is that it is virtually impossible to combine climbing the postdoctoral ladder with having children. Provision of better childcare facilities is helpful. But it is by no means sufficient, as most women who want children also want to play some part in bringing them up.

The career structure for young scientists must be made more family-friendly. This means, for example, making part-time work a real possibility, emphasizing quality rather than quantity of output, and taking career breaks properly into account when judging candidates for appointments and promotions.

These changes would benefit male as well as female postdocs. Many young male scientists would like to have stable relationships and families, see their partners from time to time and help bring up their children.

If these quality-of-life issues are not addressed, then initiatives aimed at bringing more women into science are to a large extent pointless, and brave words about equal opportunities are mere window dressing. Indeed, it could be regarded as unethical to encourage young women to embark on a career that they are unlikely to wish to continue beyond the age of 30 .

Timothy J. Roper, Larissa Conradt Department of Biology and Environmental Sciences, John Maynard Smith Building, University of Sussex, Brighton BN1 9QG, UK e-mail: t.j.roper@sussex.ac.uk

\section{Flags of convenience shield polluters in battle to protect seas}

SIR - One of the most toxic substances ever deliberately put into the sea, the marine-paint additive tributyltin (TBT), has potentially entered its final chapter. An International Maritime Organization (IMO) convention aimed at phasing out its use on vessels came into effect in September, a year after the minimum requirements for ratification were reached. However, will this International Convention on the Control of Harmful Antifouling Systems on Ships see an end to the most efficient antifoulant ever produced?

Since the 1960s, TBT has been used as a biocide in antifouling paints on the hulls of vessels.

But the discovery of toxic effects in non-target species, especially molluscs, led to the global restriction of this chemical, in the late 1980 s, to vessels that were more than 25 metres in length. These restrictions seemed to be successful, with molluscan populations returning to the levels they were before TBT usage began, in all but heavily polluted areas.

However, the IMO sought a complete ban on TBT. For this to be ratified, $25 \%$ of member states - representing $25 \%$ of the world's shipping tonnage needed to be signatories. These double requirements were met when Panama signed in September last year, ending a quest that had lasted more than a decade.

Why was acceptance so slow and the signatory states so reluctant? For a start, there are no suitable alternatives to TBT. Copper, the next best realistic alternative, does not have the widespread biocidal properties of TBT and requires more frequent application, meaning more time spent by the vessel out of the water and greater expense.

Another reason is that most of the world's shipping sails under 'flags of convenience'. This Law of the Sea loophole means that shipping companies can register their vessels in countries where costs are lower and shipping laws, including restrictions on TBT, are only loosely policed. Motivation to sign the antifouling convention is limited in the case of countries providing these 'flags'. Now that the convention has finally come into effect, it may still prove difficult to get the signatory states to implement and enforce domestic legislation.

Regrettably, TBT's effects may continue to be felt for some time to come.

Scott P. Wilson Centre for Environmental Management, CQUniversity Australia, PO Box 1319, Gladstone, Queensland 4680, Australia e-mail: s.wilson@cqu.edu.au 